\title{
REVEALING CHANGES IN THE TECHNICAL PARAMETERS OF THE TEAT CUP LINERS OF MILKING MACHINES DURING TESTING AND PRODUCTION CONDITIONS
}

\author{
Andriy Paliy $\bowtie$ \\ Department of Technical Systems and Animal Husbandry Technologies ${ }^{1}$ \\ paliy.andriy@ukr.net \\ Elchyn Aliiev \\ Department of Mechanization of Production Processes in Animal Husbandry \\ Dnipro State Agrarian and Economic University \\ 25 Sergei Efremov str., Dnipro, Ukraine, 49600 \\ Anatoliy Paliy \\ Laboratory of Veterinary Sanitation and Parasitology \\ National Scientific Center "Institute of Experimental and Clinical Veterinary Medicine» \\ 83 Pushkinska str., Kharkiv, Ukraine, 61023 \\ Katerina Ishchenko \\ Department of Technical Systems and Animal Husbandry Technologies ${ }^{1}$ \\ Igor Lukyanov \\ Department of Equipment and Engineering of Processing and Food Production ${ }^{1}$ \\ Volodymyr Dobrovolsky \\ Department of Physiology, Biochemistry and Morphology \\ State Agrarian and Engineering University in Podilia \\ 13 Schevchenko str., Kamianets-Podilskyi, Ukraine, 32316 \\ Oksana Yurchenko \\ Department of Construction Technology ${ }^{2}$ \\ Oleksandr Chekan \\ Department of Obstetrics and Surgery ${ }^{2}$ \\ Tetiana Dedilova \\ Department of Economics and Entrepreneurship \\ Kharkiv National Automobile and Highway University \\ 25 Yaroslava Mudrogo str., Kharkiv, Ukraine, 61002

\section{Yurii Musiienko} \\ Department of Obstetrics and Surgery ${ }^{2}$ \\ ${ }^{1}$ Kharkiv Petro Vasylenko National Technical University of Agriculture \\ 44 Alchevskih str., Kharkiv, Ukraine, 61002 \\ ${ }^{2}$ Sumy National Agrarian University \\ 160 Herasyma Kondratieva str., Sumy, Ukraine, 40021
}

$\triangle$ Corresponding author

\section{Abstract}

To implement effective cow milking, it is necessary to take into account the peculiarities of the milk flow process, the milking machine's adaptability to perform the given technological functions.

The aim of research is to establish changes in the design and technological parameters and physical and mechanical properties of teat cup liner of milking machines during its testing and in production conditions. The results obtained will make it possible to make a rational choice of rubber, ensure an efficient milking process during its service life. 
It is found that the tensile strength of silicone teat cup liner at the beginning of operation was 1.6 times higher than that of a rubber compound, and after 6 months. operation - 1.7 times. With respect to the relative elongation, this difference was 1.4 times, and after operating time -1.3 times.

Studies have proven that rubber during operation changes its physical and mechanical properties: the length of the active part increased by $3.1 \mathrm{~mm}$; wall thickness $-0.2 \mathrm{~mm}$. It is found that the most intensively elastic properties of teat cup liner changed during the first 10-20 days. After 10 days, the closing vacuum increased by $16.6 \%$ compared to the initial one, and after 20 days by $23.3 \%$, which amounted to 8.57 and $9.06 \mathrm{kPa}$, respectively. Up to 420 hours of operation, the clamping vacuum reached $11.3 \mathrm{kPa}$, which is $5.8 \%$ lower than the requirements for toughening teat cup liner for rejection. In general, over the period of experiments, the average value of the vacuum of closing the opposite walls of teat cup liner increased from 7.35 to $12.43 \mathrm{kPa}$, which is $3.6 \%$ higher than the norm (12 $\mathrm{kPa}$ ).

As a result of experimental studies, the regularity of the rubber tension force depending on the operating time in the form of a fourth degree polynomial is obtained. It is found that after 150 hours of operation, the tensile force of teat cup liner decreased by $21 \%$.

Keywords: teat cup liner, rubber parameters, operating time, service life, tensile force.

DOI: $10.21303 / 2461-4262.2021 .002056$

\section{Introduction}

Livestock is one of the largest and leading sectors of agricultural production. In this regard, the solution of food problems in many respects takes place with its effective development, namely, with the development of dairy cattle breeding.

One of the main technological processes of dairy cattle breeding is the machine milking of cows. So machine milking directly affects the amount of milk received and its quality. To do this, it is necessary to take into account the peculiarities of the milk flow process of cows, the milking machine's adaptability to perform the specified technological functions, regardless of the method of machine milking. If the parameters do not match during the milking of cows, a violation of the regime occurs, due to which malnutrition occurs, injuries to the nipples, and diseases of the udder appear [1,2].

The consequences of using teat cup liner that does not meet the zootechnical, sanitary and hygienic and international technical and technological requirements (ISO 3918, ISO 5707, ISO 6690) is a significant technological effect on the microstructure of milk and the physiological state of animals [3].

It has been established [4] that insufficient compression of teat cup liner does not completely open or close the milk canal of udder milking. Hyperkeratosis, blue nipples, ring formation at the base, and other injuries appear. This leads to bacterial diseases, the emergence and progress of mastitis. The very signal in violation of the milking regime is that the level of milk yield is noticeably reduced, the animal begins to behave nervously.

The material from which rubber is made has operational limitations. First of all, this refers to the intervals of replacing the current one with a new one. There is publicly available data in which it is possible to draw a relationship between the number of dairy cows and the number of milking [5].

But, as noted by researchers [6], in production they use teat cup liner without taking into account natural wear and tear. This can lead to serious consequences. So, due to rubber breakthroughs, milk or water will enter the pump during washing. If this was a long process, then rust, gouges, grooves may begin to form inside the vacuum pump.

The analysis of numerous experiments [7-9] indicates that it is extremely important to exploit the highest quality and most affordable type of teat cup liner.

Comparative studies of various milking-dairy systems $[10,11]$ show that the liner of milking machines with technical and technological parameters that do not correspond to the physiological needs of animals can lead to different types of mastitis.

Improving the efficiency of the use of rubber products in milking machines is to achieve not only the well-known advantages of modern production. The advantages include: increased productivity and intensity of use of milking equipment, reduced labor costs and energy consumption of products, but also the technological effect by creating the most favorable conditions for animals.

The works $[1,4,11]$ is devoted to the study of the issues of operation and functioning of milking and dairy equipment. But there were still unresolved issues related to the study of the design 
and technological parameters of teat cup liners made of various materials. The reason for this is the objective difficulties associated with access to dairy complexes, the expenditure side in terms of the timing of the relevant studies and tests.

So, in order to maximize the performance of the device and protect the mammary gland from the negative influence of vacuum pressure during milking, the condition of teat cup liner must comply with physiological, veterinary and technical requirements. Namely, to promote:

- active withdrawal of milk with a minimum latency period;

- stimulation of the milk return reflex and its stimulation;

- withdrawal of milk at a vacuum pressure, which is safe for the mammary gland, while maintaining the required productivity.

Thus, the use of milking machines with the best technical characteristics of teat cup liners, which are able to maintain the milk flow reflex during milking at a sufficiently high level, is an integral factor in obtaining premium milk and a reserve for increasing the milk productivity of cows.

Previous studies have established that not all liners meet the physiological needs of the animal and cause a number of negative effects during milking [12].

Most of the shortcomings can be eliminated by conducting appropriate studies aimed at establishing changes in the design and technological parameters and physical and mechanical properties of teat cup liners of milking machines, and will increase the efficiency of machine milking of cows.

Thus, it is possible to increase the efficiency of the manifestation of the genetic potential of milk production in cows by ensuring a full-fledged process of mammary gland secretion and milk flow. At the same time, the manufacturability of milking equipment, namely teat cup liner, is of decisive importance. In recent years, the market saturation with a large variety of rubber products, both domestic and foreign, makes it difficult to choose for use in teat cups. The information available in the literature on the detection of changes in the technical parameters of teat cup liners of milking machines during testing and production conditions does not give a comparative assessment and is extremely contradictory.

The constructive and technological characteristics of teat cup liners are factors that have a determining character of the work of rubber during the milking process, and, as a consequence, its effect on the animal's body. Therefore, the rubber products of milking machines must be given due attention.

Consequently, the need for these studies is to identify changes in the technical parameters of teat cup liners made from various materials in production conditions. This is achieved through comparative technical tests of rubber products.

This approach will make it possible to expand the understanding of the technical and technological characteristics of rubber products. Along with this, it will allow to reveal the mechanism of changes in the technical parameters of teat cup liners during use, is of practical value.

The aim of research is to establish changes in the design and technological parameters and physical and mechanical properties of teat cup liners of milking machines during its testing and in production conditions.

To achieve this aim, the following objectives are solved: materials;

- to compare the design and technological parameters of teat cup liners made of various

- to establish changes in the technical parameters of teat cup liners depending on its service life.

\section{Materials and methods}

The objects of research are:

- BouMatic teat cup liner (analogue DD.00.041A) made of food-grade silicone material produced by BouMatic Robotics, Moncton (Canada);

- teat plate DD 00.041A made of rubber material produced by JSC «Bratslav» town. Bratslav, Nemirovsky district, Vinnytsia region (Ukraine).

The choice of these products for research is explained by the fact that they are widely represented on the milking equipment market and are in demand in Ukraine [12]. 
The first stage of experimental research included the determination of the following parameters and properties of teat cup liner during its service life:

- physical and mechanical properties (tensile strength, relative and permanent elongation);

- dynamics of changes in the mass of teat cup liner during its constant and periodic contact with liquid media (milk, water, solutions of detergents, washing-disinfectants and disinfectants) and air.

The study of the dynamics of changes in the mass of teat cup liner during its constant and periodic contact with liquid media was carried out in water $(\mathrm{pH}=7.5 \pm 0.5)$, milk with a fat content of $3.2 \pm 1 \%$ at a temperature of $20 \pm 2{ }^{\circ} \mathrm{C}$. Along with this used a solution of an acid detergent from Ekolat (Germany) at a temperature of $55 \pm 5^{\circ} \mathrm{C}$ for 150 days [13]. The detergent was used at a concentration of $0.5 \%$ (200 liters of working solution were prepared from $1 \mathrm{~kg}$ of concentrate).

According to the methods $[12,13]$, samples were taken, initial inspection of products, suitability for testing was established, and rubber was rejected.

The elastic properties of teat cup liners were determined once every ten days. Along with this, the following indicators of the quality of teat cup liners were taken into account: the length of the active part (mm), the diameter of the suction cup ( $\mathrm{mm})$, the thickness of the walls of the working part (mm), the change in the geometric shape of the product.

Control over the operation of teat cup liners during the study was carried out in accordance with [14].

Determination of the elastic properties of teat cup liners in the sleeve of a teat cup was carried out using a device, the diagram of which is shown in Fig. 1, b. The control of vacuum pressure was carried out using the «Milking machine tester» (Ukraine), the general view of which is shown in Fig. 1, $\boldsymbol{a}$. The Milking machine tester is designed to simplify testing of dairy milking equipment in dairy farms in accordance with ISO 3918, ISO 5707, ISO 6690. The main functions are to measure vacuum, its pulsations and air flow in milking installations. Measurements of vacuum pressure: range $-0-100 \mathrm{kPa}$; absolute error $-0.6 \mathrm{kPa}$; pressure sensor response time $-2.5 \mathrm{~ms}$. Ripple measurements: the range for the ripple frequency is $40-200$ pulses $/ \mathrm{min}$; absolute error for the ripple frequency -1 pulses $/ \mathrm{min}$; the range for the ripple phases is $0-1,200 \mathrm{~ms}$. Air flow measurement: range $-0-3,000 \mathrm{l} / \mathrm{min}$; absolute error $-5 \mathrm{l} / \mathrm{min}$; response time $-2.5 \mathrm{~ms}[15,16]$.
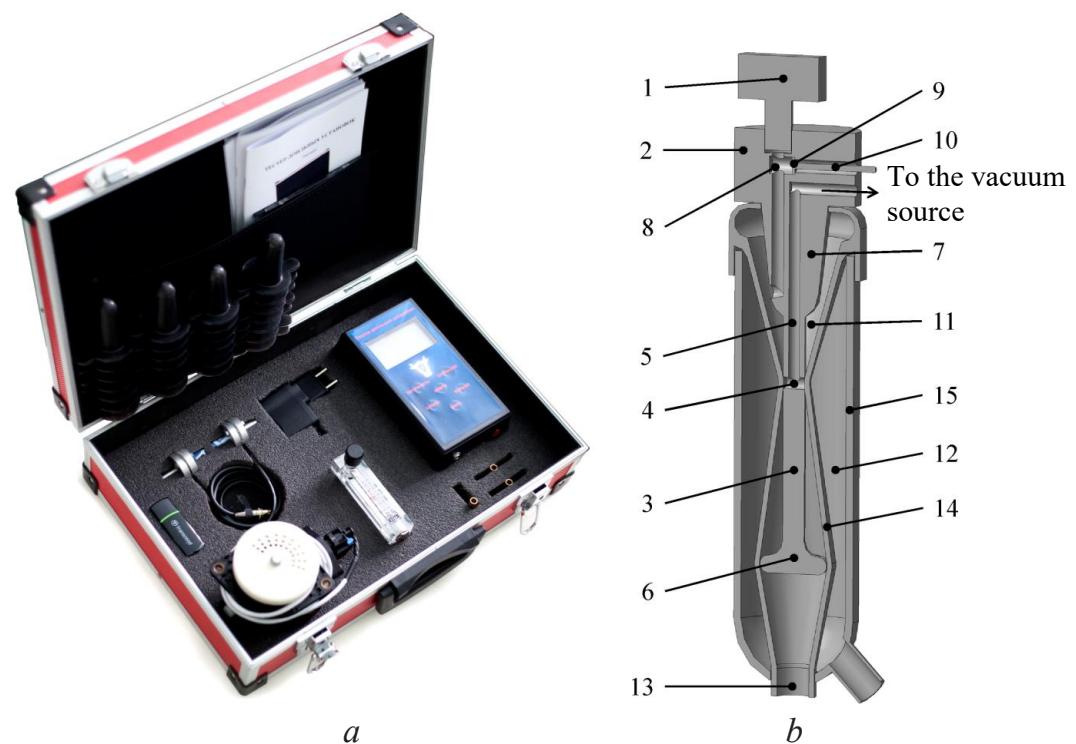

Fig. 1. Device for quality control of teat cup liners:

$a$ - general view of the «Milking machine tester»; $b$ - diagram of the device for quality control of teat cup liner; 1 - vacuum gauge pressure sensor «Milking machine tester»;

2 - artificial teat; 3 - central narrowed area; 4 - radial hole; 5 - channel; 6, 7 - extreme thickened areas; 8 - through channel; 9 - check valve; 10 - button; 11, 12 - cavities; 13 - milk tube; 14 - teat cup liner; 15 - teat cup 
The device consists of a vacuum pressure sensor «Milking machine tester»1, vacuum sources (not shown) and artificial teat 2 . Artificial teat 2 consists of a central constricted section 3 with a radial hole 4 , which is connected through channel 5 to a vacuum source, and extreme thickened sections 6 and 7. In the thickened section 7, a through channel 8 is made, which is connected to a vacuum gauge pressure sensor 1 to connect the cavity 11 to the atmosphere. In channel 8 there is a check valve 9, which has a stem with a button 10, which protrudes outward. Artificial teat 2 is introduced into the teat cup liner 14 of the teat cup 15. In this case, two cavities are formed: the cavity 11 between the artificial teat 2 and the teat cup liner 14 and the cavity 12 between the teat cup 15 and the teat cup liner 14, which is connected to the atmosphere. A milk tube 13 is supplied to the teat cup 15. The device operates as follows: when the vacuum source is turned on, the check valve 9 closes. Under the influence of the pressure difference in the cavities 11 and 12, the liner 14 closes and closes the radial opening 4, thereby separating the cavity 11 from the vacuum source. According to the readings of the vacuum pressure sensor 1, the elasticity of teat cup liner is judged. After the end of the determination of the elasticity of teat cup liner, press on the rod protruding outward, with the button 10 opening the check valve 9 . As a result, the value from the vacuum pressure sensor 1 takes its original position (zero) [17].

The tensile force of teat cup liner was determined using a PCE FG 200 dynamometer (error $-0.01 \mathrm{~N}$ ) in accordance with GOST 270-75.

Studies to determine the tensile force of teat cup liner from the time of operation were carried out according to the observation plan $[N, R(r, T)]$. According to the plan, tests of $N$ objects begin at the same time; objects that have failed during testing are replaced with new ones. Observations are stopped when the number of objects that failed has reached the value $r$ or when the observation time or time $T$.

The number of objects of observation for experimental research was determined by the formula:

$$
N=\chi \cdot \frac{\overline{t_{0}}}{\overline{t_{k}}},
$$

where $\chi$-tabular coefficient; $\overline{t_{0}}$ - mean time between failures; $t_{k}$-duration of observations.

The number of objects of observation for experimental studies was 20 . The mathematical model of the influence of the tension force and the vacuum value of the closing of the opposite walls of teat cup liner on the operating time is presented in the form of regression equations - polynomial:

$$
y=\sum_{i=0}^{n} a_{i} \cdot t^{i},
$$

where $a_{i}$ - regression coefficients; $t$ - operating time, h; $h$ - technical parameter of teat cup liner.

\section{Results}

\section{1. Results of comparing the design and technological parameters of teat cup liners}

The results of changes in the physical and mechanical properties of BouMatic teat cup liners (analogous to DD.00.041A) from food grade silicone material and DD 00.041A teat cup liner from rubber material produced by JSC Bratslav before and after operation at the dairy complex are presented in Table $\mathbf{1 .}$

Table 1

Dynamics of physical and mechanical properties of teat cup liners during operation

\begin{tabular}{ccccc}
\hline \multirow{2}{*}{ Indicators } & \multicolumn{2}{c}{ DD 00.041A teat cup liner } & \multicolumn{2}{c}{ BouMatic teat cup liner } \\
\cline { 2 - 5 } & $\begin{array}{c}\text { before } \\
\text { operation }\end{array}$ & $\begin{array}{c}\text { after } \mathbf{6} \text { months } \\
\text { of operation }\end{array}$ & $\begin{array}{c}\text { before } \\
\text { operation }\end{array}$ & $\begin{array}{c}\text { after } \mathbf{6} \text { months } \\
\text { of operation }\end{array}$ \\
\hline Tensile strength, $\mathrm{kgf} / \mathrm{cm}^{2}$ & $92.1 \pm 2.3$ & $109.4 \pm 2.4$ & $148.2 \pm 2.1$ & $182.7 \pm 2.4$ \\
Relative extension, \% & $61.7 \pm 0.6$ & $56.9 \pm 0.7$ & $84.0 \pm 0.7$ & $72.1 \pm 0.7$ \\
Relative residual elongation, \% & $20.1 \pm 0.4$ & $28.2 \pm 0.5$ & $14.3 \pm 0.3$ & $17.4 \pm 0.5$
\end{tabular}


It was found that teat cup liner made of food grade silicone slightly prevails in terms of the main physical and mechanical characteristics of teat cup liner made of a rubber compound. So the tensile strength at the beginning of operation was 1.6 times more about the product with a rubber compound, and after 6 months. operation -1.7 times.

As for the relative permanent elongation, it has a slight difference.

Data on the study of the kinetics of rubber swelling in liquid media are shown in Fig. 2.

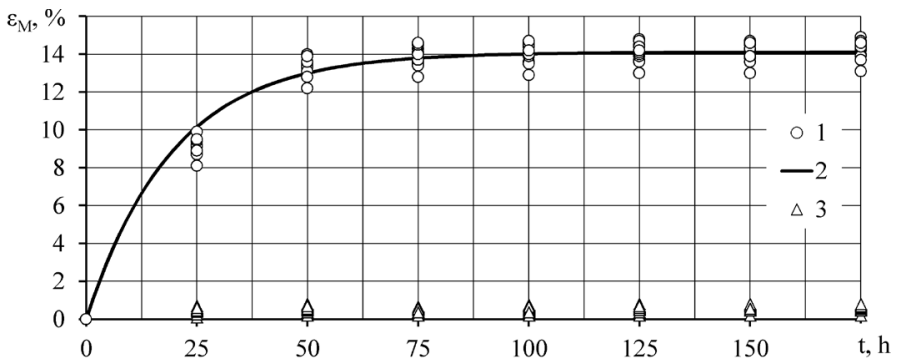

Fig. 2. Change in the mass of teat cup liner during continuous presence in milk: 1 - teat cup liner DD 00.041A from the material of rubber compound produced by JSC «Bratslav»; 2 - the equation $\varepsilon_{M}(t)=14.1(1-\exp (-0.051 \cdot t)) ; 3$ - BouMatic teat cup liner (analogue DD.00.041A) made of food-grade silicone material «BouMatic Robotics»

In Fig. 2 it can be seen that the mass of a product made of rubber compounds increases over 60 days when it is kept in milk up to $14.3 \%$ and remains at this level within 175 hours. The data obtained can be approximated in the form of an exponential equation (Fig. 2, graph 2), the correlation coefficient is 0.99 . In turn, silicone rubber during the experiment practically did not change its weight $(0-0.8 \%)$. As seen in Fig. 3 silicone rubber in production conditions reduces weight from the first day of the study to $0.7 \%$ and does not restore it during the entire observation.

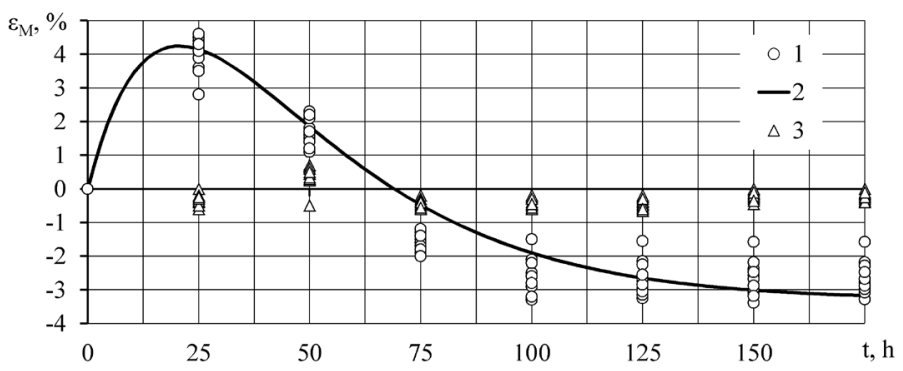

Fig. 3. Change in the mass of teat cup liner during periodic exposure to milk, acid detergent from Ekolat and water: 1 - DD 00.041A teat cup liner made of rubber compound material produced by Bratslav OJSC; $2-\varepsilon_{M}(t)=-3.3+0.8(t-4.8) \exp (-0.039 \cdot(t-4.8)) ; 3-$ BouMatic teat

cup liner (analogue of DD.00.041A) made of «BouMatic Robotics» food grade silicone

Teat cup liners made from rubber compounds, under similar conditions, increase their weight during the first 25 hours to $4.6 \%$. Up to 62 hours, its mass reaches the primary level, then it sharply decreases and up to 125 hours, the weight loss is $3.4 \%$. The data obtained can be approximated in the form of an exponential equation (Fig. 3, graph 2), the correlation coefficient is 0.98.

\section{2. Investigation of changes in technical parameters of teat cup liners during operation}

The technical condition of teat cup liners during operation is determined by such parameters as tension force, elongation, clamping vacuum. The high correlation between elongation and clamping vacuum $(0.95-0.98)$ allows to take mad as a generalized parameter to characterize the technical condition of teat cup liner samples.

An analysis of the change in the magnitude of the closing vacuum of the opposite walls of teat cup liners during operation is shown in Fig. 4. As a result of data approximation, let's obtain a polynomial equation: 


$$
\Delta P(t)=-2 \cdot 10^{-10} t^{4}+3 \cdot 10^{-7} t^{3}-0.0001 t^{2}+0.0266 t+8.0659, R=0.97,
$$

where $R$ - correlation coefficient.

It was found that the most intensively elastic properties of teat cup liner changed during the first 10-20 days. After 10 days (44 hours of operating time), the closing vacuum increased in comparison with the initial one by $16.6 \%$, after 20 days (93 operating hours) - by $23.3 \%$, which amounted to 8.57 and $9.06 \mathrm{kPa}$, respectively.

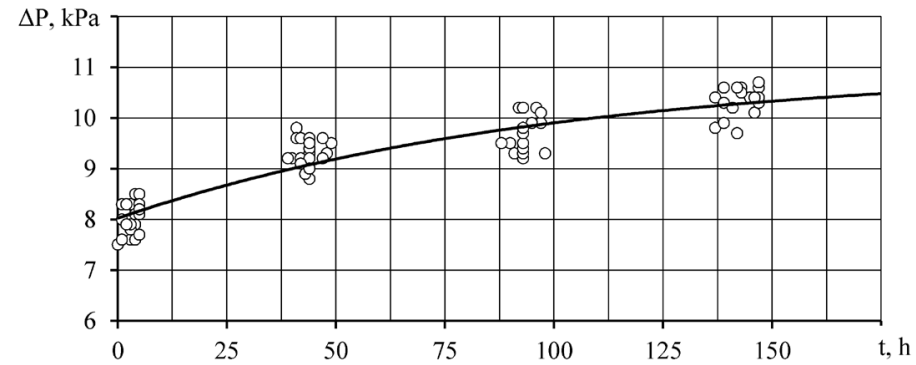

Fig. 4. Dynamics of the closing vacuum value $\Delta P(t)$ from the duration of operation

Up to 420 hours of operation, the clamping vacuum reached $11.3 \mathrm{kPa}$, which is $5.8 \%$ lower than the requirements for toughening teat cup liner for rejection.

In general, over the period of experiments, the average value of the vacuum of closing the opposite walls of teat cup liner increased from 7.35 to $12.43 \mathrm{kPa}$, which is $3.6 \%$ higher than the norm $(12 \mathrm{kPa})$. Along with the hardening of teat cup liner, changes in such design parameters as the length of the active part, the inner diameter of the suction cup, and the wall thickness (mm) were taken into account.

The analysis of measurements showed that in the course of the experiment the diameter of the suction cup practically did not change $(24.8-24.9 \mathrm{~mm})$, and the length of the active part after 105 days, or 487 hours of operation, increased from 140.1 to $143.2 \mathrm{~mm}$.

The thickness of the walls of the rubber until it was replaced in the experimental group with a new one increased by $0.2 \mathrm{~mm}$ from the initial one and amounted to $2.0 \mathrm{~mm}$.

As a result of the approximation of the experimental data, a polynomial dependence of the change in the tension force of teat cup liner on the duration of operation was obtained (Fig. 5):

$$
F_{H}(t)=1 \cdot 10^{-7} t^{4}-3 \cdot 10^{-5} t^{3}+0.0017 t^{2}-0.072 t+60.249, R=0.98
$$

The established empirical dependence of the change in the tensile strength of the tire $F t(t)$ on the duration of operation allows at any time to determine its actual technical condition. Thus, after 150 hours of operation, the tensile strength of teat cup liner decreased by $21 \%$.

After analyzing the operation of teat cup liner from the standpoint of reliability, the main indicators of reliability were established: the probability of failure-free operation $P(t)$, failure rate $\lambda(t)$, failure density $f(t)$ and failure time $t_{0}$. According to the obtained data, graphs of reliability indicators for teat rubber were constructed (Fig. 6).

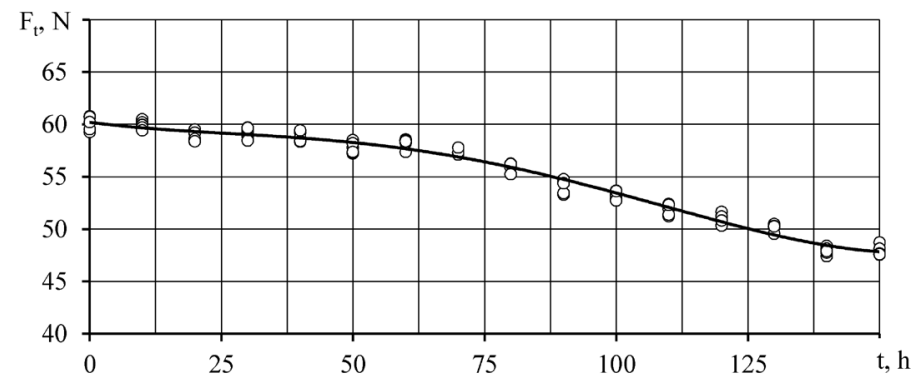

Fig. 5. Dynamics of the tensile strength of teat cup liner $F t(t)$ from the duration of operation 


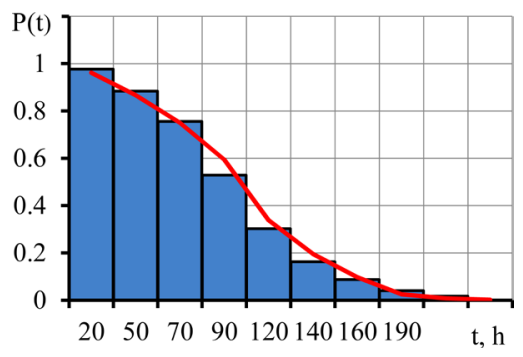

a

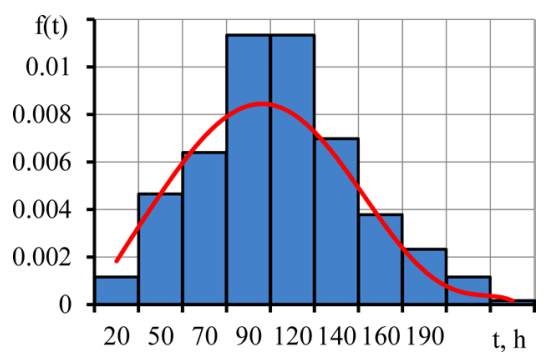

b

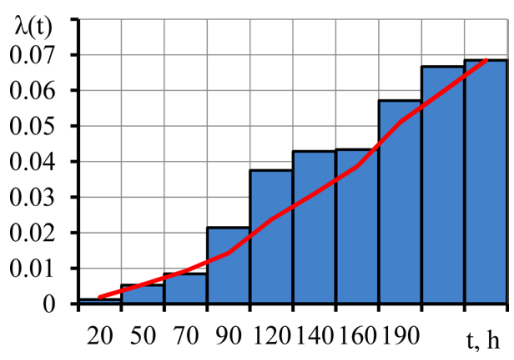

c

Fig. 6. Indicators of reliability of teat rubber:

$a$ - probability of failure-free operation $P(t) ; b$ - failure rate $\lambda(t) ; c$ - failure density $f(t)$

Calculations of the correlation coefficient and visual analysis of graphs in Fig. 6 show that the most reliable models describing the failure density distribution for the elements of the vacuum system is the law of normal distribution (Table 2).

Table 2

Correlation and regression coefficients of teat cup liner reliability indicators

\begin{tabular}{ccccc}
\hline $\begin{array}{c}\text { Linear regression } \\
\text { coefficient } \boldsymbol{A}\end{array}$ & $\begin{array}{c}\text { Linear regression } \\
\text { coefficient } \boldsymbol{B}\end{array}$ & $\begin{array}{c}\text { Correlation } \\
\text { coefficient } \boldsymbol{r}\end{array}$ & $\begin{array}{c}\text { Mean time } \\
\text { to failure } \boldsymbol{a}\end{array}$ \\
\hline 0.919 & 0.093 & 0.967 & 101 \\
deviation $\boldsymbol{\sigma}$
\end{tabular}

Studies have confirmed the assumptions about the choice of theoretical distribution laws. If to analyze the level of reliability, then from the graphs shown in Fig. 6, it is seen that teat cup liner has the highest number of failures within 90-120 hours. The level of failure of teat cup liner decreases with increasing operating time.

\section{Discussion}

The teat cup liner of milking machines is one of the intermediate links between the animal and the installation. For this reason, extremely stringent requirements are imposed on it [18-20]. So, the initial stage of research was the comparative technical tests of teat cup liners.

It has been established (Table 1) that teat cup liner made of food grade silicone slightly prevails in terms of the main physical and mechanical characteristics of rubber made of a rubber compound. At the same time, the mass of a product made of rubber compounds increases over 60 days when it is kept in milk up to $14.3 \%$ and remains at this level within 175 hours (Fig. 2).

It has been found (Fig. 3) that silicone rubber in production conditions reduces the mass from the first day of the study to $0.7 \%$ and does not restore it during the entire observation.

At the next stage of the research, the goal was to set the change in the technical parameters of teat cup liner depending on its service life. The change in the magnitude of the vacuum of closing the opposite walls of teat cup liner during operation (Fig. 4) has been analyzed, and as a result of data approximation, let's obtain the polynomial equation (3). Also, as a result of the approximation of the experimental data, a polynomial dependence of the change in the tension force of teat cup liner on the duration of operation was obtained (Fig. 5).

After analyzing the operation of teat cup liner from the standpoint of reliability, the main indicators of reliability have been established (Fig. 6), and the performed calculations of the correlation coefficient and visual analysis of the graphs show that the most reliable models describing the density distribution at failure for elements of a vacuum system is the normal distribution law (Table 2).

The results obtained fully reveal the estimated technical indicators of the milking machine's teat cup liner. Along with this, the mechanism of changing the performance characteristics of rubber products is highlighted. Thanks to this, the problem is solved in the rational choice of teat cup liner.

It should be noted that the methodological approach for determining the magnitude of the clamping vacuum using the developed device for quality control of teat cup liner and the «Milking 
machine tester» (Fig. 1) is innovative. This is due to the obtaining of values with a minimum interval of fluctuations, which allows to accurately set the parameter value.

As a result of experimental studies, a regularity of the tension force of teat cup liner has been obtained depending on the operating time in the form of a polynomial of the fourth degree. It has been found that after 150 hours of operation, the tensile force of teat cup liner decreased by $21 \%$. Based on the results of experimental studies of the operation of teat cup liner in production conditions from the standpoint of reliability, the main indicators of its reliability have been established: the probability of failure-free operation $P(t)$, the failure rate $\lambda(t)$, the density of failures $f(t)$ and the mean-between-failures $T_{0}$. So for teat cup liner within 90-120 hours, the largest number of failures occurs.

The comprehensive studies carried out allow to assert that rubber products have a wide range of values in terms of the main technical and technological indicators. This confirms the fact that attention must be paid to teat cup liner in order to ensure optimal milking of cows.

The research results are consistent with the studies carried out earlier [12, 15, 17, 21], supplement them in the format of obtaining the latest information for the use of innovative technical solutions (Fig. 1). A significant difference in the methodological plan of the research carried out was that it was possible to set the change in the design and technological parameters and physical and mechanical properties of the rubber of milking machines during its testing and in production conditions. Along with this, due to the significant variability and variability of the design parameters of teat cup liner, difficulties arise in the general solution of the issue of full compliance of the rubber product with the physiological needs of the milking herd. This remains an unresolved issue in the technological chain of obtaining high-quality milk.

Studies aimed at establishing the influence of teat cup liner of milking machines on cows during milking and on the quality of milk seem to be promising. Namely, on the physiological state of the teats of the udder of animals and the general bacterial contamination of the resulting milk.

\section{Conclusions}

It has been found that the tensile strength of silicone teat cup liner at the beginning of operation was 1.6 times higher than that of a rubber compound, and after 6 months of operation -1.7 times. With respect to the relative elongation, this difference was 1.4 times, and after operating time -1.3 times.

During operation, teat cup liner changes its physical and mechanical properties: the length of the active part increased by $3.1 \mathrm{~mm}$; wall thickness $-0.2 \mathrm{~mm}$. It has been found that the most intensively elastic properties of teat cup liner changed during the first 10-20 days. After 10 days, the closing vacuum increased by $16.6 \%$ compared to the initial one, and after 20 days by $23.3 \%$, which amounted to 8.57 and $9.06 \mathrm{kPa}$, respectively. Up to 420 hours of operation, the clamping vacuum reached $11.3 \mathrm{kPa}$, which is $5.8 \%$ lower than the requirements for toughening teat cup liner for rejection. In general, over the period of experiments, the average value of the vacuum of closing the opposite walls of teat cup liner increased from 7.35 to $12.43 \mathrm{kPa}$, which is $3.6 \%$ higher than the norm $(12 \mathrm{kPa})$.

As a result of experimental studies, a regularity of the tension force of teat cup liner has been obtained depending on the operating time in the form of a polynomial of the fourth degree. It has been found that after 150 hours of operation, the tensile force of teat cup liner decreased by $21 \%$. Based on the results of experimental studies of the operation of teat cup liner in production conditions from the standpoint of reliability, the main indicators of its reliability have been established: the probability of failure-free operation $P(t)$, the failure rate $\lambda(t)$, the density of failures $f(t)$ and the mean-between-failures $T_{0}$. So for teat cup liner within 90-120 hours, the largest number of failures occurs.

\section{References}

[1] Wieland, M., Virkler, P. D., Borkowski, A. H., Älveby, N., Wood, P., Nydam, D. V. (2019). An observational study investigating the association of ultrasonographically assessed machine milking-induced changes in teat condition and teat-end shape in dairy cows. Animal, 13 (2), 341-348. doi: https://doi.org/10.1017/s1751731118001246

[2] Palii, A. P., Kovalchuk, Y. O., Boyko, Y. A. (2020). Impact of various milking equipment on incidence of mastitis in dairy herd. Ukrainian Journal of Ecology, 10 (5), 160-165. doi: https://doi.org/10.15421/2020_224

[3] Shevchenko, I. A, Aliyev, E. B. (2013). Scientific and methodical recommendations on multicriteria production control of milking parlors. Zaporozhye: Accent Invest-trade, 156. Available at: http://aliev.in.ua/doc/knigi/kniga_1.pdf 
[4] Odorčić, M., Rasmussen, M. D., Paulrud, C. O., Bruckmaier, R. M. (2019). Review: Milking machine settings, teat condition and milking efficiency in dairy cows. Animal, 13, s94-s99. doi: https://doi.org/10.1017/s1751731119000417

[5] Kuhnhenne, M., Pyschny, D., Kramer, L., Brieden, M., Ummenhofer, T., Ruff, D. C. et. al. (2019). Mechanical and thermal performance of new liner tray solutions. Steel Construction, 12 (1), 23-30. doi: https://doi.org/10.1002/stco.201800025

[6] Leonardi, S., Penry, J. F., Tangorra, F. M., Thompson, P. D., Reinemann, D. J. (2015). Methods of estimating liner compression. Journal of Dairy Science, 98 (10), 6905-6912. doi: https://doi.org/10.3168/jds.2015-9380

[7] Dmytriv, V., Dmytriv, I., Lavryk, Y., Horodeckyy, I. (2018). Models of adaptation of the milking machines systems. BIO Web of Conferences, 10, 02004. doi: https://doi.org/10.1051/bioconf/20181002004

[8] Demba, S., Elsholz, S., Ammon, C., Rose-Meierhöfer, S. (2016). The Usability of a Pressure-Indicating Film to Measure the Teat Load Caused by a Collapsing Liner. Sensors, 16 (10), 1597. doi: https://doi.org/10.3390/s16101597

[9] Biradar, D., Abraham, J., Sachin, S., Koundinya, U. (2020). Development of Milking Systems and its Impact on Milk Quality. International Journal of Livestock Research, 8 (12), 1-12. doi: https://doi.org/10.5455/ijlr.20180317120751

[10] Besier, J., Lind, O., Bruckmaier, R. M. (2015). Dynamics of teat-end vacuum during machine milking: types, causes and impacts on teat condition and udder health - a literature review. Journal of Applied Animal Research, 44 (1), $263-272$. doi: https://doi.org/10.1080/09712119.2015.1031780

[11] Paliy, A. P., Nanka, O. V., Lutcenko, M. M., Naumenko, O. A., Paliy, A. P. (2018). Influence of dust content in milking rooms on operation modes of milking machine pulsators. Ukrainian Journal of Ecology, 8 (3), 66-70. Available at: https://www.ujecology.com/articles/influence-of-dust-content-in-milking-rooms-on-operation-modes-of-milkingmachine-pulsators.pdf

[12] Paliy, A., Nanka, A., Marchenko, M., Bredykhin, V., Paliy, A., Negreba, J. et. al. (2020). Establishing changes in the technical parameters of nipple rubber for milking machines and their impact on operational characteristics. Eastern-European Journal of Enterprise Technologies, 2 (1 (104)), 78-87. doi: https://doi.org/10.15587/1729-4061.2020.200635

[13] TU 2539-007-76503135-2011. Soskovaya rezina DD 00.041A dlya komplektatsii doil'nyh stakanov (2011). Available at: https://docs.cntd.ru/document/437156326

[14] GOST 9.030-74. Unified system of corrosion and ageing protection. Vulcanized rubbers. Method of testing of resistance to attack by corrosive media in limp state. Available at: https://docs.cntd.ru/document/1200015025

[15] Shevchenko, I. A., Aliev, E. B. (2013). Automated control systems for technical processes in dairy farming. Annals of Warsaw University of Life Sciences - SGGW. Agriculture (Agricultural and Forest Engineering), 61, 41-49. Available at: http://aliev. in.ua/doc/stat/2013/stat_4.pdf

[16] Milking machine tester. Operation manual (2013). Zaporozhye, 36. Available at: http://aliev.in.ua/doc/rozrobki/tester/ tester_ekspluataciya.pdf

[17] Paliy, A., Naumenko, A., Paliy, A., Zolotaryova, S., Zolotarev, A., Tarasenko, L. et. al. (2020). Identifying changes in the milking rubber of milking machines during testing and under industrial conditions. Eastern-European Journal of Enterprise Technologies, 5 (1 (107)), 127-137. doi: https://doi.org/10.15587/1729-4061.2020.212772

[18] Fahim, A., Kamboj, M., Sirohi, A., Bhakat, M., Prasad, S., Gupta, R. (2018). Milking machine induced teat reactions in crossbred cows milked in automated herringbone milking parlour. Indian Journal of Animal Sciences, 88 (12), 1412-1415.

[19] Gálik, R., Bod’o Š Staroňová, L. (2016). Monitoring the inner surface of teat cup liners made from different materials. Research in Agricultural Engineering, 61 (Special Issue), S74-S78. doi: https://doi.org/10.17221/50/2015-rae

[20] Xu, Y., Feng, L., Cong, H., Li, P., Liu, F., Song, S., Fan, L. (2020). Preparation of $\mathrm{TiO}_{2} /$ Ser filler with ultraviolet resistance and antibacterial effects and its application in SBR/TRR blend rubber. Journal of Rubber Research, 23 (2), 47-55. doi: https://doi.org/ 10.1007/s42464-020-00035-X

[21] Palyi, A. P., Makshei, A. N., Kasianenko, O. I., Petrov, R. V., Faly, L. I., Palyi, A. P. (2020). Distribution, bioecological peculiarities of staphylinids (Coleoptera, Staphylinidae) in livestock biocenoses of forest-steppe and steppe Ukraine. Biosystems Diversity, 28 (1), 24-28. doi: https://doi.org/10.15421/012004

Received date 13.01.2021

(C) The Author(s) 2021

Accepted date 04.09.2021

Published date 18.11.2021

This is an open access article under the Creative Commons CC BY license

How to cite: Paliy, A., Aliiev, E., Paliy, A., Ishchenko, K., Lukyanov, I., Dobrovolsky, V., Yurchenko, O., Chekan, O., Dedilova, T., Musiienko, Y. (2021). Revealing changes in the technical parameters of the teat cup liners of milking machines during testing and production conditions. EUREKA: Physics and Engineering, 6, 102-111. doi: https://doi.org/10.21303/2461-4262.2021.002056 